(Aus der medizinischen Klinik der Universität Heidelberg.)

\title{
Über die Durchgängigkeit menschlicher Blutkörper für Zucker.
}

Von

\section{Ernst Masing.}

Nach den vorliegenden Untersuchungen ${ }^{1}$ ) wird zu Menschenblut zugesetzter Traubenzucker teilweise auch von den roten Blutkörpern aufgenommen. Ich habe darauf nachzuweisen gesucht, dass das Teilungsverbältnis $\frac{\text { Prozent Zucker in den Blutkörpern }}{\text { Prozent Zucker in der Zwischenflüssigkeit }}$ zwischen 0,5 und 0,7 schwankt und zwar anscheinend kleiner mit steigender Zuckerkonzentration wird. Ferner zeigte es sich, dass ein konstantes Teilungsverhältnis sich nicht sofort einstellt, sondern dass der Ausgleich eine gewisse, bei niedriger Temperatur sehr beträchtliche Zeit braucht.

Wie die unten angeführten Versuche lehren, dringen auch andere Zuckerarten, und zwar sämtliche untersuchten Monosaccharide, in menschliche Blutkörper ein. Die Geschwindigkeit des Eindringens ist für manche Zucker allerdings erheblich geringer als für den Traubenzucker; dagegen ist das Teilungsverhältnis nach erreichtem Gleichgewicht stets annähernd das gleiche, das ist ungefähr 0,6. Dis accharide (Rohrzucker, Milchzucker, Maltose) dringen unter den angegebenen Bedingungen überhaupt nicht merklich ein. Wir haben also hier einen Fall vor uns, in dem Verdoppelung der Molekülgrösse das Eindringen in die Zelle vollständig verhindert. Ferner ermöglicht das für alle eindringendèn Zucker gleiche Teilungsverhältnis die Grösse der "wässerigen Phase" im Blutkörperchen abzuschätzen.

1) Rona und Doeblin, Biochem. Zeitschr. Bd. 31 S. 215, - Masing, Pflüger's Arch. Bd. 149 S. 227. - A. Loeb, Biochem. Zeitschr. Bd. 49 S. 413.

2) Über die Verteilung von Traubenzucker usw. Pflüger's Arch. Fd. 156 S. 401. 


\section{Monosaccharide.}

Die untenstehende Tábelle enthält die Resultate, die sich beim Mischen von Monosacchariden mit Menschenblut ergaben, übersichtlich zusammengestellt; einige genauere Versuchsprotokolle befinden sich im Anhang. Da, wie oben erwähnt, die Zuckerkonzentration - das gilt wenigstens für Traubenzucker - das Teilungsverhältnis etwas beeinflusst, gebe ich im fünften Stab der Tabelle Anhaltspunkte zur Beurteilung der Zuckerkonzentration in den vorliegenden Versuchen. Meist wurde $0,1 \mathrm{~g}$ Zucker zu $20 \mathrm{ccm}$ Blut zugesetzt, in einigen Versuchen doppelt und dreimal so viel; doch dürften diese Versuche trotzdem gut mit den anderen vergleichbar sein, da nach früheren Versuchen die Dextrosekonzentration etwa auf das 15 fache gesteigert werden müsste, wenn das Teilungsverhältnis um $25 \%$ abnehmen sollte. Wahrscheinlich ist also der Fehler, der durch mässige Konzentrationsunterschiede bedingt wird, nur gering; er kommt auch auf der Tabelle nicht merklich zum Ausdruck. Unter "Daner des Versuchs" (Stab 3) ist die Zeit zu verstehen, während der die Blutkörper mit der Zuckerlösung in Berührung standen, bis das Gemisch in die Zentrifuge kam.

\begin{tabular}{|c|c|c|c|c|c|}
\hline $\begin{array}{l}\text { Versuch } \\
\text { Nr. }\end{array}$ & Zuckerart & $\begin{array}{c}\text { Dauer } \\
\text { des } \\
\text { Versuchs }\end{array}$ & $\begin{array}{l}\text { Versuchs- } \\
\text { temperatur }\end{array}$ & $\begin{array}{c}\text { Zuckerkon- } \\
\text { zentration } \\
0,1 \text { gZucker } \\
\text { auf Kubik- } \\
\text { zentimeter } \\
\text { Blut }\end{array}$ & $\begin{array}{l}\text { Teilungsverhältnis : } \\
\text { Proz. Zneker i. d. Blntkörpern } \\
\text { Proz. Zucker i. d. Z Z Fischentl. }\end{array}$ \\
\hline $\begin{array}{r}3 \\
4 \\
5 \\
6 \\
7 \\
8 \\
9 \\
10 \\
11 \\
12 \\
13 \\
14\end{array}$ & $\begin{array}{l}\text { Xylose } \\
\text { Rhamnose } \\
\text { Arabinose } \\
\quad " \\
" \\
\text { Galaktose } \\
\text { Mannose } \\
\text { Lävulose } \\
" \\
" \\
" \\
"\end{array}$ & $\begin{array}{l}1 / 2 \mathrm{~h} \\
1 \mathrm{~h} \\
1 \mathrm{~h} \\
1 \mathrm{~h} \\
1 / 2 \mathrm{~h} \\
1 \mathrm{~h} \\
1^{3 / 4 h} \\
2^{\mathrm{h}} \\
2 \mathrm{~h} \\
1^{1 / 2 h} \\
1{ }^{1 / 2 h} \\
1 \mathrm{~h} \\
1 / 2 \mathrm{~h} \\
2 \mathrm{~h} \\
2 \mathrm{~h} \\
4 \mathrm{~h} \\
1^{1 / 2} \\
2^{\mathrm{h}}\end{array}$ & $\begin{array}{c}\text { Zimmertemp. } \\
" \\
38^{\circ} \\
\text { Zimmertemp. } \\
38^{\circ} \\
38^{\circ} \\
\text { Zimmertemp. } \\
" \\
38^{\circ} \\
\text { Zimmertemp. } \\
" \\
" \\
38^{\circ} \\
38^{\circ}\end{array}$ & $\begin{array}{r}20 \\
20 \\
20 \\
21 \\
20 \\
20 \\
20 \\
21 \\
10 \\
15 \\
15 \\
21 \\
20 \\
20 \\
7 \\
7 \\
14 \\
10\end{array}$ & $\begin{array}{c}0,6-0,7 \\
0,6-0,7 \\
0,5-0,6 \\
0,65 \\
0 \\
\left.0,15^{1}\right) \\
\left.0,66^{1}\right) \\
0,65^{1} \\
0,62 \\
0,62 \\
0,69 \\
0,58 \\
0,3 \\
0,3 \\
\left.0,27^{1}\right) \\
0,46 \\
\left.0,58^{1}\right) \\
\left.0,68^{1}\right)\end{array}$ \\
\hline
\end{tabular}

1) Vgl. die entsprechende Versuchsnummer im Anhang. 
Zur Untersuchung kamen drei Pentosen (Xylose, Rhamnose, Arabinose) und drei Hexosen (Galaktose, Mannose, Lävulose).

Vier von diesen Monosacchariden, und zwar Xylose, Ramnose, Galaktose und Mannose, verhalten sich, wie die Tabelle zeigt, menschlichen Blutkörpern gegenüber durchaus ähnlich dem Traubenzucker. Schon bei Zimmertemperatur- verteilen sie sich verhältnismässig schnell auch auf die Blutkörper. Sieht man letztere, wie das bei Verteilungsstudien üblich ist, als pauschales Lösungsmittel an, so wird nach $1 / 2-1$ Stunde ein Teilungsverhältnis erreicht.

Prozent Zucker in den Blutkörpern

Prozent Zucker in der Zwischenflüssigkeit'

das zwischen 0,6 und 0,7 liegt und durch längere Dauer des Versuchs oder durch Erwärmung des Systems sich nicht mehr verändert. So ist das Teilungsverhältnis für Xylose bei Zimmertemperatur nach 1/2 Stunde etwas über 0,6 und nach 1 Stunde nicht grösser; das für Rhamnose nach 1 Stunde Versuchsdauer bei $38^{\circ}$ nicht wesentlich höher als bei Zimmertemperatur. - Galaktose erreichte in $1^{1 / 2}$ Stunden bei Zimmertemperatur ein Teilungsverbältnis von 0,62 ; ein besonderer Versuch zeigte mir, dass sich Galaktose schon in 30 Minuten bei Zimmertemperatur so verteilt, dass einstündige Erwärmung der Mischung an der Verteilung nichts mehr ändert. Das Gleichgewicht wird also auch schon bei Zimmertemperatur recht schnell erreicht.

Wesentlich langsamer dringen Arabinose und Lävulose ein. Nach $1 / 2$ Stunde hat sich bei Zimmertemperatur die Arabinosekonzentration in der Zwischenflüssigkeit noch nicht merklich geändert, das Teilungsverhältnis ist 0 (Versuch Nr. 4); nach 1 Stunde fand sich ein Teilungsverhältnis von 0,15 (Versuch Nr. 5), nach $1^{3 / 4}$ Stunden und 2 Stunden bei $38^{\circ} \mathrm{C}$. ergab sich 0,66 und 0,65 , war also das Gleichgewicht erreicht. Ganz ähnliches sehen wir bei der Lävulose: im Versuch Nr. 14 nach 2 Stunden bei Zimmertemperatur 0,27 , nach 4 Stunden 0,46 , und erst nach 2 Stunden bei $38^{\circ}$ C. (Versuch Nr. 16) 0,68 .

Ich habe seinerzeit angegeben ${ }^{1}$, dass Traubenzucker von menschlichen Blutkörpern nichț etwa nur an der Oberfläche adsorbiert wird, sondern eindringt und osmotisch in den Blutkörpern wirksam wird,

1) Pflüger's Arch. Bd. 149. 
in isotoniseher Lösung zu Volumvermehrung und Hämolyse führt. Auch in Lösungen der übrigen Monosaccharide lässt sich eine Volumenzunahme menschlicher Blutkörper hämatokritisch leicht nachweisen.

In Glasröhren von etwa $5 \mathrm{~mm}$ innerer Weite wurden je $1 \mathrm{ccm}$ eines dicken Blatkörperbreies mit $1 \mathrm{ccm}$ einer $5 \%$ igen Zuckerlösung und ein Tropfen Serum, wodurch die Agglutination der Blutkörper verhindert wird und die Zwischenflüssigkeit die passende Reaktion erhält, gemischt und nach einiger Zeit etwa $1 / 2$ Stunde lang scharf zentrifugiert. Die Höhe der Blutsäule konnte dann als Maass des Blutkörpervolumens dienen. Zur Kontrolle wurde immer eine Blutprobe mitzentrifugiert, die mit Ringer-Lösung statt der Zuckerlösung versetzt war. War die Blutsäule in der Zuckerlösung mit dem Millimeterstab gemessen wesentlich höher als in der Ringer-Lösung, so war Zucker eingedrungen; auf diese Weise liess sich auch die relative Geschwindigkeit, mit der die verschiedenen Zucker eindringen, ad oculos darstellen.

Zum Beispiel:

16. Juli. Vier gleichweite Glasröhren werden mit je 1 ccm Blutkörperbrei beschickt; in die eine Ringer-Lösung, in die anderen drei Zuckerlösungen mit etwas Serum gebracht. Nach gründlichem Durchmischen stehen die Proben 23 Min. bei Zimmertemperatur und werden dann 30 Min. lang zentrifugiert. Nach Ausmessung der Höhe der Blutsäule (a) werden alle Proben wieder durchgemischt, 30 Min. im Wasserbade von $33^{\circ}$ gehalten und dann 30 Min. zentrifugiert. Es ergibt sich das Volumen $b$.

Röhre 1-1 ccm Blutkörperbrei $+1,1 \mathrm{ccm}$

Höhe der Blutsäule nach dem Zentrifugieren

Ringer . . . . . . . . . . .

Röhre 2-1 ccm Blutkörperbrei $+1,1 \mathrm{ccm}$

$5 \%$ iger Dextrose +1 Tropfen Serum.

Röhre 3-1 ccm Blutkörperbrei $+1,1 \mathrm{ccm}$

$5 \%$ iger Galaktose +1 Tropfen Serum .

Röhre 4-1 cem Blutkörperbrei + 1,1 ccm

$5 \%$ iger Laevulose +1 Tropfen Serum.

$25,5 \mathrm{~mm} \quad 25,0 \mathrm{~mm}$

$35,5,48,5$,

$50,5,49,5$,

$29,5 \quad 41,5 \quad$ "

Nach 23 Min. langem Stehen bei Zimmertemperatur (a) ist das Volumen der Blutkörper in der Laevuloselösung nur wenig, in der Dextroselösung erheblich, in der Galaktoselösung stark vermehrt. 30 Min. lange Erwärmung hebt diesen Unterschied nahezu auf, wenn auch das Laevuloseblut noch etwas zurückgeblieben ist. Also dringt auch bei dieser Versuchsanordnung die Laevulose am langsamsten ein.

16. Juli. Vier gleiche Glasröhren werden mit je $1 \mathrm{ccm}$ Blutkörperbrei und je ein Tropfen Serum beschickt, mit Ringer-, Arabinose-, Rhamnosè- und Xyloselösung versetzt, durchgemischt, stehen 20 Min. bei Zimmertemperatur und werden 30 Min. scharf zentrifugiert. Ablesung des Blutkörpervolumens (a). Dann werden sie wieder durchgemischt, stehen $15 \mathrm{Min}$. in körperwarmem Wasser und werden 25 Min. lang scharf zentrifugiert; es ergibt sich das Volumen $b$. 
Röhre 1-1 ccm Blutkörperbrei + $1 \mathrm{ccm}$ Ringer......... .

Röhre 2-1 ccm Blutkörperbrei $+1 \mathrm{ccm}$ $5 \%$ iger Arabinose . . . . . . .

Röhre 3-1 ccm Blutkörperbrei $+1 \mathrm{ccm}$ $5 \%$ iger Rhamnose . . . . . . .

Röhre 4-1 ccm Blatkörperbrei +1 ccm $5 \%$ iger Xylose

Höhe der Blutsäule nach dem Zentrifugieren

a

b

$26,5 \mathrm{~mm} \quad 25,5 \mathrm{~mm}$

$27,5 \quad 33,5 . \quad$,

$48,5 \quad \begin{gathered}47,5 \\ \text { haemolytisch }\end{gathered}$

Erst nach zweistündigem Stehen bei $38^{\circ}$ erreichten die in der Arabinoselösung suspendierten Blutkörper ein Volumen, das in der Xylose- und Rhamnoselösung schon bei Zimmertemperatar in 20 Min. erreicht wurde. - Auch hier also volle Übereinstimmung mit den Ergebnissen der Zuckerbestimmungen, d. h. verhältnismässig langsames Eindringen der Arabinose.

Alle untersuchten Monosaccharide dringen also in menschliche Blutkörper ein, wenn auch verschieden schnell. Alle verteilen sich so auf Blutkörper und Zwischenflüssigkeit, dass ein annähernd konstantes Teilungsverhältnis, das für die angewandten Konzenträtionen zwischen 0,6 und 0,7 liegt, erreicht wird. Durch längere Dauer des Versuches oder durch Erwärmung lässt sich dieses Verhältnis nicht mehr verändern. - Am langsamsten dringen Arabinose und Lävulose ein.

\section{Disaccharide.}

Die im Anhang ausführlich wiedergegebenen Versuche Nr. 17, 21 und 22 zeigen, dass Rohrzucker, Milchzucker und Maltose nicht oder jedenfalls nicht in nachweisbarer Menge von menschlichen Blutkörpern aufgenommen werden; in vollem Gegensatz zu den Monosacchariden. Auch Erwärmen der Blutkörper-Zuckermischung ändert daran nichts.

1. $45 \mathrm{ccm}$ Menschenblut werden zentrifugiert, $20 \mathrm{ccm}$ Serum durch $10 \mathrm{ccm}$ Ringer und $10 \mathrm{ccm}$ einer $10 \%$ igen Saccharoselösung ersetzt. Die Mischang steh't 30 Min. bei Zimmertemperatur und wird zentrifugiert. $10 \mathrm{cem}$ der Zwischenflüssigkeit werden abgehoben, auf $40 \mathrm{ccm}$ verdünnt, enteiweisst und polarisiert: Drehung $+1,03^{\circ}$ in $18,9 \mathrm{~cm}$ langer Röhre.

Der Rest wird durchgemischt, steht in körperwarmem Wasser $3 / 4$ Stunden and wird zentrifugiert. $10 \mathrm{ccm}$ der Zwischenflüssigkeit ebenso wie oben behandelt: Drehung $+1,03^{\circ}$.

2. $20 \mathrm{ccm}$ Blutkörperbrei mit $17 \mathrm{ccm} \mathrm{Ringer}$ und $3 \mathrm{ccm}$ einer $10 \%$ igen Maltoselösung versetzt, stehen $1 / 2$ Stunde bei Zimmertemperatur und werden zentrifugiert. 
5 cem Zwischenflüssigkeit enteiweisst ergeben nach Bertrand auf Zucker verarbeitet $5,5 \mathrm{ccm}$ Permanganat.

Der Rest wird durchgemischt, steht 1 Stunde bei $38^{\circ}$, wird wieder stark zentrifugiert:

5 ccm Zwischenflüssigkeit ergeben $5,8 \mathrm{ccm}$ Permanganat,

$5 \mathrm{ccm}$ des Blutkörperbreies ebenso verarbeitet ergeben $0,3 \mathrm{ccm}$ Permanganat.

Auch bei Körpertemperatur ist die Maltose nicht in die Blutkörper eingedrungen.

Im Auhang finden sich aus einer grösseren Reihe herausgegriffene Versuchsbeispiele, je eins für jede Zuckerart, die als Beleg für das Gesagte dienen mögen. Die übrigen Versuche sind natürlich in gleichem Sinne ausgefallen.

In guter Übereinstimmung findet man in hämatokritischen Versuchen keine deutliche Volumvermehrung Blutkörper in annähernd isotonischen Lösungeı von Disacchariden.

Vier gleiche Glasröhren werden mit je 1 ccm Blutkörperbrei und 1,1 ccm 9\% iger Disaccharidlösung beschickt, stehen $1 / 2$ Stunde in körperwarmem Wasser und werden dann $1 / 2$ Stunde scharf zentrifugiert.

Höhe der Blutkörpersäule nach dem Zentrifugieren

Röhre $1-1$ ccm Blutkörperbrei $+1,1 \mathrm{ccm}$ Ring e r . . $25,5 \mathrm{~mm}$

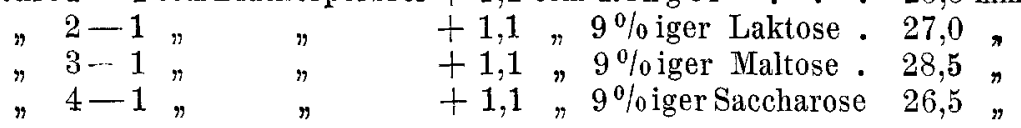

Also keine wesentlichen Volumenunterschiede gegenüber der Ring e r-Kontrolle. -

\section{Methodik.}

Die Methodik der Zuckerbestimmungen war im wesentlichen dieselbe wie in meinen früheren Arbeiten.

Das Volumen der Formelemente in den Blutproben wurde durch $2 \mathrm{~N}$-Bestimmungen in der Zwischenflüssigkeit vor und nach Verdünnung durch Ringer-Lösung festgestellt. $\mathrm{Zu}$ einer zweiten abgemessenen Blutprobe wurde dann der betreffende Zucker meist in $10 \%$ iger Lösung zugesetzt; die Mischung stand eine Zeitlang bei Zimmertemperatur, wo es nötig erschien, auch bei Körpertemperatur, und wurde darauf scharf zentrifugiert. In einer abgemessenen Menge der Zwischenflüssigkeit wurde der Zuckergehalt nach Enteiweissung mit kolloidalem Eisenhydroxyd $\left(\mathrm{NaH}_{2} \mathrm{PO}_{4}\right.$ als fällender Elektrolyt) durch Polarisation oder durch Reduktion nach der Bertrand'schen Methode bestimmt.

Dann setzte ich die gleiche Zuckermenge zu einer genau abgemessenen Menge Serum, die gerade so gross war, wie die (berechnete) Menge Serum in der Blutprobe, und bestimmte in gleicher Weise den Zuckergehalt. Ergab diese Mischung das gleiche Resultat wie die Zwischenflüssigkeit der Blutprobe, so war kein Zucker eingedrungen, 
differierte sie deutlich, so musste Zucker an die Formelemente gegangen sein. Meist wurde auch der Zuckergehalt des abzentrifugierten Blutkörperbreies bestimmt.

Die nach der Bertrand'schen Methode in Milligramm Cu gewonnenen Analysenwerte wurden zunächst nach der Bertrand'schen Reduktionstabelle auf Traubenzucker umgerechnet. Um die gewünschten Zahlen für die übrigen Zucker zu erhalten, benutzte ich die von $\mathrm{Grube}$ im A bderhald en 'schen Handbuch der biochemischen Arbeitsmethoden ${ }^{\mathbf{1}}$ ) angegebenen Vergleichswerte. Nach diesen verhält sich die Reduktionskraft gleicher Gewichtsmengen in annähernd gleich starken Lösungen folgendermaassen: Dextrose . . . . . 105,2

\begin{tabular}{|c|c|c|c|}
\hline Lävulose. & . & & \\
\hline Galaktose. & - & . & . \\
\hline Laktose & . & . & \\
\hline Maltose & & . & \\
\hline
\end{tabular}

Nach eigenen Bestimmungen war die entsprechende Zahl für Mannose ungefähr gleich $100^{2}$ ).

Für die Pentosen sind meines Wissens keine ausführlichen Reduktionstabellen vorhanden. Eigene Bestimmungen an meinen Präparaten ${ }^{8}$ ) ergaben :

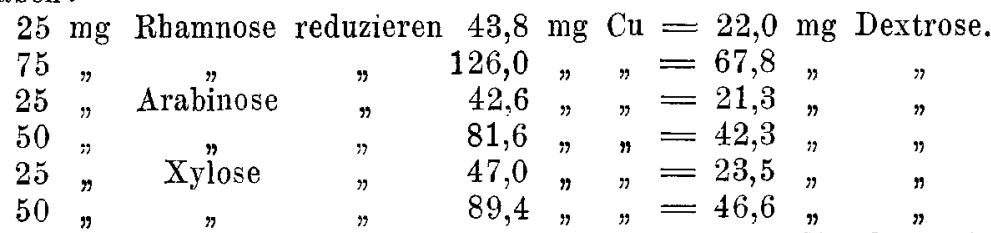

Meine Pentosen reduzierten also etwas schwächer als Traubenzucker; die Beziehungen zwischen Zuckermenge und reduziertem Kupfer waren annähernd dieselben wie beim Traubenzucker, d. h. grössere Zuckermengen reduzierten verhältnismässig etwas weniger Kupfer.

Trotz dieser Übereinstimmung habe ich auf eine Berechnung meiner Pentosenzahlen nach der Traubenzuckertabelle verzichtet, die Resultate meiner Pentosenbestimmungen in Milligramm Kupfer ausgedrückt und mit ibnen so operiert, als wenn sie proportional den tatsächlichen Zuckerzahlen wären. Das ist natürlich nicht ganż richtig, weil eine strenge Proportionalität zwischen Kupfer und Zucker ni cht besteht. Doch ist der Fehler gering, weil meine Pentosenbestimmungen sich innerhalb recht enger Konzentrationsgrenzen bewegen. Es kam ja für meine Zwecke (Teilungsverhältnis !) nicht auf grosse Genauigkeit an

\section{Versuchsprotokolle.}

In Interesse der Raumersparnis gebe ich nur einige Beispiele; die übrigen Versuche sind in ganz ähnlicher Weise angelegt und durchgeführt worden.

1) Bd. 2 S. 167.

2) Beleg: $25 \mathrm{mg}$ Mannose reduzieren $47,4 \mathrm{mg} \mathrm{Cu}=23,8 \mathrm{mg}$ Dextrose. 50 $92,0, \eta=48,0$,

3) Es waren Kahlbaum 'sche Präparate, die nicht weiter gereinigt wurden; die folgenden Zahlen erheben keinen Auspruch auf grosse Genauigkeit. 


\section{Nr. 5.}

27. Juli 1913. $20 \mathrm{ccm}$ normalen Menschenblutes $(8,84 \mathrm{ccm}$ Blutkörper und $11,16 \mathrm{ccm}$ Serum) werden zentrifugiert, $6 \mathrm{ccm}$ Serum durch $5 \mathrm{ccm}$ Ringer-Lösung and $1 \mathrm{ccm}$ einer 10\% igen ArabinoseLösung ersetzt; die Mischung steht 1 Stunde bei Zimmertemperatur und wird zentrifugiert: $10 \mathrm{ccm}$ Zwischenflüssigkeit und $10 \mathrm{ccm}$ Blutkörperbrei.

2,5 cem Zwischenflüssigkeit reduzieren $34,0 \mathrm{mg} \mathrm{Cu}$ (abgel. 6,8 ccm Perm.) 2,5 "Blutkörperbei " $\quad 8,5,(n 1,7, "$ ") Darin $0,29 \mathrm{ccm} Z$ wischenflüssigkeit ent-

sprechend . . . . . . . . 4,0, "

2,21 ccm Blutkörper müssen reduzieren $\overline{4,5 \mathrm{mg} \mathrm{Cu}}$

$2,5 " n$ " $" 5,1$ " "

$5,16 \mathrm{ccm}$ Serum

$+5,0 \Rightarrow$ Ring e $\mathrm{r}$ - Lösung

$+1,0 \# 10 \%$ ige Arabinoselösung

$11,16 \mathrm{ccm}$, davon $2,5 \mathrm{ccm}$ reduzieren $37 \mathrm{mg} \mathrm{Cu}$ (abgel. 7,4 ccm Perm.) $2,5 \mathrm{ccm}$ Zwischenflüssigkeit reduz. 34

Aus $2,5 \mathrm{ccm}$ Zwischenflüssigkeit ver-

schwunden Arabinose entsprechend $3 \mathrm{mg} \mathrm{Cu}$

Es sind also nur sehr geringe Mengen Arabinose aus der Zwischenflüssigkeit verschwunden und in den Blutkörpern nachweisbar geworden. Die Arabinosekonzentration in den Blutkörpern beträgt $1 / 7-1 / 6$ der der Zwischenflüssigkeit.

\section{Nr. 6.}

24. November 1913. $20 \mathrm{ccm}$ Menschenblut $(9,86$ ccm Blutkörper und $10,14 \mathrm{ccm}$ Serum) werden zentrifugiert, $5 \mathrm{ccm}$ Serum durch 4 ccm $0,9 \%$ ige NaCl-Lösung und $1 \mathrm{ccm}$ einer $10 \%$ igen Arabinoselösung ersetzt; das Gemisch steht $1^{3} / 4$ Stunden im Wasserbade bei $38^{\circ}$ and wird dann 25 Minuten zentrifugiert: $8 \mathrm{ccm}$ Zwischenflüssigkeit werden entfernt, der Restbrei durchgerührt.

2,5 ccm Zwischenflüssigkeit reduzieren 24,0 mg Cu (abgel. 4,1 ccm Perm.) 2,5 "Blutkörperbrei $\quad 17,4 \quad "\left(\begin{array}{llll} & 3,0,0)\end{array}\right.$ Darin enthalten $0,45 \mathrm{ccm}$ Zwischen-

flüssigkeit, entsprechend . . . $\frac{4,4 n n}{13,0 \mathrm{~m}, \mathrm{Cn}}$

Also 2,05 ccm Blutkörper reduzieren $13,0 \mathrm{mg} \mathrm{Cu}$

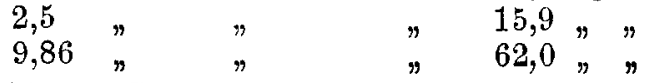

$5,14 \mathrm{ccm}$ Serum

$+4,0 \quad 0,9 \%$ ige NaCl-Lüsung

$+1,0 \% 10^{\circ}$ \% ige Arabinoselösung

$10,14 \mathrm{ccm}$ gemischt. 
Davon 2,5 c cm reduzieren . . . $42 \mathrm{mg} \mathrm{Cu}$ (abgel. 7,1 ccm Perm.) 2,5 \# Zwischenflüssigk. reduz. 24 , "

Aus $2,5 \mathrm{ccm}$ Zwischenflüssigkeit verschwunden Arabinose entsprechend $18 \mathrm{mg} \mathrm{Cu}$ Aus 10,14 ccm Zwischenflüssigkeit . . 77 , "

Es ist also reichlich Zucker aus der Zwischenflüssigkeit verschwunden und zum grössten Teil in den Blutkörpern nachweisbar geworden. Das Teilungsverhältnis beträgt etwa 0,66 .

\section{Nr. 14.}

21. September 1913. $20 \mathrm{ccm}$ Menschenblut $(8,87 \mathrm{ccm}$ Blutkörper und $11,13 \mathrm{ccm}$ Serum) werden zentrifugiert, $5 \mathrm{ccm}$ Serum durch $2 \mathrm{ccm}$ R ing e r-Lösung und $3 \mathrm{ccm}$ einer $10 \%$ igen Lävuloselösung ersetzt; das Gemisch steht 2 Stunden bei Zimmertemperatur und wird dann $1 / 2$ Stunde zentrifugiert.

$5 \mathrm{ccm}$ Zwischenflüssigkeit enth. $108 \mathrm{mg}$ Lävulose (abgel. 19,4 ccm Perm.) 5 "Blutkörperbrei " 38 " " $($ "6,4 " $)$ 5 " Blutkörper \# 29 " " (berechnet)

Das Verhältnis $\frac{\text { Prozent Lävulose in den Blutkörpern }}{\text { Prozent Lävulose in der Zwischenflüssigkeit }}$ war also $=0,27$.

Die nicht verarbeiteten Reste der Zwischenflüssigkeit und des Blutkörperbreis werden gemischt und stehen nach Zusatz einer Spur Natriumfluorid noch weitere 2 Stunden bei Zimmertemperatur; zentrifugiert.

$5 \mathrm{ccm}$ Zwischenflüssigkeit enth. $92 \mathrm{mg}$ Lävalose (abgel. 16,8 ccm Perm.)

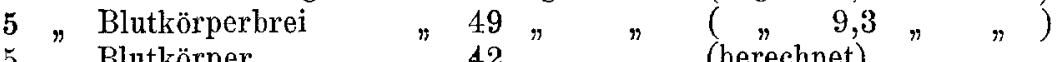
5 " Blutkörper " 42 " (berechnet)

Das Teilungsverhältnis hat sich offenbar geändert, es beträgt 0,46 ; in der Zwischenflüssigkeit ist weniger, in den Blutkörpern mehr Zucker nachweisbar als 2 Stunden vorher.

\section{Nr. 15.}

27. November 1913. Zu $13 \mathrm{ccm}$ normalen Menschenblutes $(6,41 \mathrm{ccm}$ Blutkörper und 6,59 cem Serum) wird $1 \mathrm{ccm}$ einer $10 \%$ igen Lävuloselösung zugesetzt, gemischt, $1^{1 / 2}$ Stunden bei $38^{0} \mathrm{im}$ Wasserbade gehalten, dann 1/2 Stunde zentrifugiert: $6,2 \mathrm{ccm}$ Zwischenflüssigkeit und $7,8 \mathrm{ccm}$ Blutkörperbrei.

$5 \mathrm{ccm}$ Zwischenflüssigkeit enth. 36,4 mg Lävulose (abgel. 5,8 ccm Perm.)

5 "Blutkörperbrei " 23,3 " " 3,8 " " Darin $0,8 \mathrm{ccm}$ Zwischenflüssigk. 5,8 ",

Also in $4,2 \mathrm{ccm}$ Blutkörper $17,5 \mathrm{mg}$ Lävulose

" 5,0 " $, 20,8$,. .

5 cem Blutkörper haben demnach etwa $21 \mathrm{mg}$ Lävulose aufgenommen; daraus ergibt sich als Teilungsverhältnis für die genannte Konzentration $\frac{\text { Prozent Lävulose in den Blatkörpern }}{\text { Prozent Lävulose in der Zwischenflüssigkeit }}=0,58$. 
Nr. 16.

25. September 1913. Zu 5,5 ccm einer Suspension normaler Menschenblutkörper, die $4,67 \mathrm{ccm}$ Blutkörper enthält, werden $4 \mathrm{ccm}$ Ringer-Lösung and $1 \mathrm{ccm}$ einer $10 \%$ igen Lävuloselösung zugesetzt; die Mischung steht 2 Stunden im Wasserbade von $38^{\circ} ; 1 / 2$ Stunde zentrifugiert: $5 \mathrm{ccm} Z$ wischenflüssigkeit und $5,5 \mathrm{ccm}$ Blutkörperbrei. $5 \mathrm{ccm}$ Zwischenflüssigkeit enth. 50,1 mg Lävulose (abgel. 9,5 ccm Perm.) 5 "Blutkörperbrei $" 36,6$ " $(" 7,1, n)$ Darin $0,75 \mathrm{~cm}$ Zwischenflüss. mit 7,5 "

Also in 4,25 ccm Blutkörp. enth. 29,0 mg Lävulose

$$
" \quad 5,0 " \quad " 34,1 \text { " } "
$$

5 ccm Blutkörper haben demnach in 2 Stunden bei Körpertemperatur $34 \mathrm{mg}$ Lävulose aufgenommen. Das Tejlungsverhältnis Prozent Lävulose in den Blutkörpern Prozent Lävulose in der Zwischenfüssigkeit $=0,68$.

\section{Nr. 17 .}

20. Juni 1913. Normales Menschenblut (45,3\% Blutkörper und $5 \pm, 7 \%$ Serum). $25 \mathrm{ccm}$ zentrifugiert, $5 \mathrm{ccm}$ Serum durch $5 \mathrm{ccm}$ $10 \%$ iger Saccharoselösung ersetzt, gemischt, 20 Minuten bei Zimmertemperatur gestanden, 30 Minuten zentrifugiert. $10 \mathrm{ccm}$ Zwischenflüssigkeit abpipettiert, anf $50 \mathrm{ccm}$ verdünnt, enteiweisst mit kolloidalem Eisenhydroxyd.

Das Filtrat gibt in einer $18,9 \mathrm{~cm}$ langen Röhre eine Drehung von $+0,86^{\circ}$ (Durchschnitt von sechs Ablesungen).

$4 \mathrm{ccm}$ derselben Zuckerlösung und $6,96 \mathrm{ccm}$ Serum (das Verlältnis der Mengen ist genau dasselbe wie oben) werden gemischt und wie oben weiter behandelt.

Das Filtrat gibt eine Drehung von $+0,89^{\circ}$.

Durch die Gegenwart von Blutlzörpern ist die Drehung also nur um $0,03^{\circ}$ geringer geworden, was wohl noch in die Fehlergrenzen fällt. - Rohrzucker dringt also unter den angegebenen Bedingungen $\mathrm{nicht}$ merklich in menschliche Blutkörper ein.

Ein zweiter Versuch mit demselben Blut gab das gleiche Resultat.

21.

27. September 1913. Normales Menschenblut. $\mathrm{Zu} 10 \mathrm{ccm}$ wird $1 \mathrm{ccm}$ einer $10 \%$ igen Milchzuckerlösung zugesetzt; gemischt, 2 Stunden im Wasserbade von $38^{\circ}$ gehalten, dann zentrifugiert: $6 \mathrm{~cm}$ $\mathrm{Z}$ wischenflüssigkeit und $5 \mathrm{ccm}$ Blutkörperbrei.

$5 \mathrm{ccm}$ Zwischenflüssigkeit enth. 64,8 $\mathrm{mg}$ Laktose (abgel. 9,3 ccm Perm.) 5 "Blutkörperbrei " 7,8 " $"$ " $1,2, "$. $\mathrm{Da}$ der Blutkörperbrei noch etwa $10 \%$ Zwischenflüssigkeit enthielt, so ist der überwiegende Teil seines Zuckergehalts durch die Zwischenflüssigkeit gedeckt. Auch bei Körpertemperatur lassen sich also nach 2 Stunden keine merklichen Mengen von Milchzucker in menschlichen Blutkörpern nachweisen. 
486 E. Masing: Über die Durchgängigkeit menschl. Blutkörper für Zucker.

Nr. 22.

23. November 1913. Menschenblut, das in $20 \mathrm{ccm} 9,86 \mathrm{ccm}$ Blutkörper und $10,14 \mathrm{ccm}$ Serum enthält. $-20 \mathrm{ccm}$ werden zentrifugiert, $5 \mathrm{ccm}$ Serum durch $2 \mathrm{ccm}$ einer $10 \%$ igen Maltos elösung und $3 \mathrm{ccm}$ einer $0,9 \%$ igen Nall-Lösung ersetzt; gemischt, $1^{3} / 4$ Stunden im Wasserbade bei $38^{\circ}$ gehalten, zentrifugiert: $9 \mathrm{ccm}$ Zwischenflüssigkeit und $11 \mathrm{ccm}$ Blutkörperbrei.

$5 \mathrm{ccm}$ Zwischenflüssigkeit enth. $77 \mathrm{mg}$ Maltose (abgel. 7,9 $\mathrm{cm}$ Perm.)

5 "Blutkörperbrei $\quad 4,5, n\left(\begin{array}{llll}n & 0,6 & n\end{array}\right.$ Darin etwa $0,5 \mathrm{ccm} Z$ wischenflüssigkeit . . . . . 7,7 " "

Der Zuckergehalt des Blutkörperbreies ist also durch den der Zwischenflüssigkeit gedeckt.

$5,14 \mathrm{ccm}$ Serum

$+2,0 \% 10 \%$ ige Maltoselösung

$+3,0 \quad 0,9 \%$ ige $\mathrm{NaCl}-\mathrm{Lösung}$

$10,14 \mathrm{ccm}$ gemischt, davon $5 \mathrm{ccm}$ enth. $78 \mathrm{mg}$ Maltose (abgel. $8 \mathrm{ccm}$ Perm.) $5 \mathrm{ccm}$ der Zwischenflüssigkeit enthalten 77 ,

Also ist aus der Zwischenflüssigkeit kein Zucker an die Blutkörper gegangen.

\section{Nachtrag.}

Die Abfassung dieser Abhandlung hat sich aus äusseren Gründen beträchtlich verzögert; ich habe beim Niederschreiben $\mathrm{zu}$ meinem Bedauern übersehen, das $\mathrm{Kozawa}$ unterdessen aus dem physiologischen Institut zu Kiel im 60. Bande der Biochemischen Zeitschrift unter dem Titel "Artdifferenzen in der Durchlässigkeit der roten Blutkörperchen" über hämatokritische Versuche berichtet hat, die den meinigen sehr ähnliche Ziele verfolgten. Kozaw a findet unter anderem, dass menschliche Blutkörperchen in isotonischen Lösungen der einfachen Zucker anschwellen, nicht dagegen in Lösungen von Disacchariden; er schliesst daraus auf Permeabilität für die ersteren und Impermeabilität für die letzteren. Unsere Resultate stimmen also durchaus überein, eine Differenz besteht nur in bezug auf die Rhamnose, die nach Kozawa nicht eindringt; vielleicht liegt das an der Verschiedenheit der benutzten Präparate. Aus Kozawa's Zahlen lässt sich ferner ableiten, dass die einfachen Zucker verschieden schnell eindringen, wenn auch Kozawa diesen Schluss selbst nicht zieht. 